\title{
Prevalence of pelvic floor dysfunction in women attending obstetrics and gynaecology OPD at PES Institute of Medical Sciences asnd Research, Kuppam
}

\author{
Ramya Gaddam, Keshav Gangadharan*, Pradeep Shivaraju, Pavan Kumar Basappa
}

Department of Obstetrics and Gynaecology, PESIMSR, Kuppam, Andhra Pradesh, India

Received: 10 October 2020

Accepted: 13 November 2020

*Correspondence:

Dr. Keshav Gangadharan,

E-mail: drgkeshav@gmail.com

Copyright: () the author(s), publisher and licensee Medip Academy. This is an open-access article distributed under the terms of the Creative Commons Attribution Non-Commercial License, which permits unrestricted non-commercial use, distribution, and reproduction in any medium, provided the original work is properly cited.

\section{ABSTRACT}

Background: Millions of women are affected with pelvic floor dysfunction globally. But when the literature was reviewed, studies assessing the prevalence of PFD (pelvic floor dysfunction) and related factors were limited in India. Hence the present study was undertaken to assess the prevalence of PFD.

Methods: 300 women aged 18-70years attending Obstetrics and Gynaecology OPD at Kuppam were interviewed and details like age, number of children, mode of delivery, BMI, education, occupation as primary outcome variables and type of pelvic floor dysfunction as explanatory variable were collected using a semi structured questionnaire. Frequency and proportions were calculated for quantitative variables and Chi-square test was used for comparison of categorical variables. p-value of $<0.05$ was considered using SPSS (Version 22).

Results: 58 out of 300 women had Pelvic floor dysfunction. Majority of them $52(17.33 \%)$ had Pelvic organ prolapse. Among them $43(74.14 \%)$ women were $>45$ years old, $38(65.52 \%)$ women had 2 or 3 children, and $12(20.69 \%)$ women had $\geq 4$ children. $47(81.03 \%)$ had vaginal delivery. $37(63.79 \%)$ subjects had no schooling and $13(22.41 \%)$ were unskilled workers. $36(62.07 \%)$ participants BMI ranged between 25 to 34.99. Age, education, occupation, number of children, mode of delivery, BMI were found to be associated with increased incidence of pelvic floor dysfunction.

Conclusions: In conclusion the study assessed high prevalence of pelvic floor dysfunction associated with vaginal delivery, increased age, number of children and BMI.

Keywords: Faecal incontinence, Pelvic floor disorders, Pelvic organs, Prevalence, Pelvic organ prolapse, Urinary incontinence

\section{INTRODUCTION}

The pelvic floor in females is required for various functions which include parturition, urination and urinary continence, defecation and faecal continence, pleasure and sexuality. Pelvic floor functions are controlled by the central nervous system and could be impaired due to anatomical injury or neurological dysfunction. Pelvic floor dysfunction is also referred to as pelvic floor disorders or pelvic floor weakness. ${ }^{1}$ Pelvic floor dysfunction is manifested as urinary incontinence (UI), faecal incontinence (FI), and pelvic organ prolapse (POP). The prevalence of PFD is estimated to be in the range of 12 to $42 \%$ and increases with age. PFDs are usually associated with a high number of pregnancies and heavy lifting. The tendency to develop PFDs increases with age due to the weakening of pelvic floor muscles mostly after the age of 55 years. ${ }^{2}$ With the advancement of age, the probability of pelvic floor dysfunction, particularly urinary or faecal incontinence increases. Among various risk factors of pelvic floor dysfunction, pregnancy and childbirth are considered to have a major 
impact. Injury to pelvic floor muscles and the connective tissue or partial denervation of the pelvic floor, which occurs due to mechanical stretching during delivery may cause PFD after delivery.

The weakening of muscles and ligaments of pelvic floor cause concavity of pelvic diaphragm and pelvic contents located on the surface of the pelvic diaphragm which causes weakening of the hammock effect. Ligament attachments also weaken, exposing the bladder and vagina to intra-abdominal pressure. This pressure may result in prolapse of uterus and vagina which disturbs natural dynamics of organs located parallel with them, namely the bladder and rectum.

This, along with increased abdominal pressure, will press the bladder neck in the opposite direction to normal physiological closure causing urine leakage. Prolapse may not be limited to bladder alone. ${ }^{3}$ Pelvic organ prolapse a type of manifestation of PFD affects $30 \%$ of women in the age group of 20-59 years. Assessing pelvic organ prolapse requires a laborious quantitative pelvic examination or imaging studies. Prolapse is one of the common indications for gynaecological surgery in developed countries. In spite of this fact, its prevalence is not studied much. The extent and consequences of pelvic floor dysfunction have also not been studied extensively. ${ }^{4}$

PFD causes social, economic, physical and psychological problems in women lowering their quality of life and productivity. With an increase in life expectancy, PFD prevalence is bound to increase, causing an economic burden on both developing and developed nations. It has been found that though PFD negatively affects the quality of life of an individual, very few women with PFD seek medical care due to many prevailing misconceptions. $81 \%$ of women with urinary incontinence, one of the main forms of manifestation of PFD, perceive the condition to be normal arising due to childbirth or age and has no treatment. Ignorance that PFD is a treatable medical condition combined with personal embarrassment attached with these conditions prevent many women from seeking medical care. ${ }^{5}$

Many factors which include female gender, age, pregnancy, childbirth, type of delivery, number of births, obesity, menopause have a role to play in aetiology of PFDs. Dysfunction of pelvic floor muscles which have important functions is found to be the major cause of PFD. Impairment of one or more of the above functions will result in PFD. ${ }^{6}$ Pelvic floor weakening depends on multiple factors, but there are a large number of predisposing factors which are preventable. Understanding clinical presentation and management of PFD will help to strengthen treatment and management practices.

The previous epidemiological studies showed global prevalence of POP between $2 \%$ and $20 \%$ among women $\leq 45$ years of age. However, estimates in developing countries vary extensively, ranging from $3.4 \%$ in South India to as high as $56 \%$ in Egypt. The weighted prevalence rate of one or more pelvic floor disorder in the United States was $25.0 \%$, including $17.1 \%$ of women with moderate-to-severe urinary incontinence, $9.4 \%$ (95\% CI 8.6, 10.2) with faecal incontinence, and $2.9 \%$ with prolapse. ${ }^{7}$ Various conditions of PFDs coexist. $16 \%$ of women with PFDs have more than one condition. It was found that $9 \%$ of women have both urinary incontinence and faecal incontinence and $7 \%$ had both urinary incontinence and pelvic organ prolapse. ${ }^{8}$

Literature has various studies on different types of pelvic floor dysfunction and their association with various risk factors. But there are very few Indian studies on the prevalence of pelvic floor dysfunction among different populations. With this background the present study is conducted with the objective to assess the prevalence of PFD and related factors in females attending outpatient at PESIMSR, Kuppam.

\section{METHODS}

The present study was a Cross-sectional study conducted among females visiting the department of Obstetrics and Gynaecology at PESIMSR, Kuppam. A sample size of 300 calculated using the formula was selected thorough convenient sampling method. The subjects were recruited from January 2018-june 2019. Females in the age group of 18-70 years were included. Females with acute illness, who had a history of recent abdominal/ gastrointestinal/ gynaecological surgery, musculoskeletal issues, spinal cord injury, cerebral palsy and who could not comprehend the questionnaire were excluded from the study. Study was approved by institutional human ethics committee. Informed written consent was obtained from all the study participants. Confidentiality of the study participants was maintained.

\section{Data collection}

All the relevant parameters were documented in a structured study proforma which was pre-tested and validated by pilot study.

The questionnaire consists of socio-demographic details, obstetric history and screening questions related to different types of urinary incontinence and anal incontinence and pelvic organ prolapse. Obstetric history included number of children and mode of delivery.

Educational qualification in women was classified as those who had no schooling, those who had primary schooling (Class 1-10), and those with secondary schooling (Class 11 and 12), undergraduates and postgraduates.

The occupation was classified as housewives, professional (Postgraduate lecturer, Lawyer, engineer), white-collar jobs (Nurse, LIC agent, Lab technician, 
School teacher, Clerical job, office accountant), skilled worker (Tailor, Beautician), semiskilled worker (Bidi rolling) and unskilled worker (Fish seller, coolie, attender, agricultural laborer).

\section{Statistical methods}

Age, number of children, education, occupation, BMI, sexual symptoms were considered as primary explanatory variables. PFD was primary outcome variable. Type of PFD was considered as the secondary outcome variable.

Descriptive analysis was carried out by mean and standard deviation for quantitative variables, frequency and proportion for categorical variables. Non-normally distributed quantitative variables were summarized by median and interquartile range (IQR). Data was also represented using appropriate diagrams like pie diagram.

All quantitative variables were checked for normal distribution within each category of explanatory variable by using visual inspection of histograms and normality Q-Q plots. Shapiro-Wilk test was also conducted to assess normal distribution AND a $p$ value of $>0.05$ was considered as a normal distribution.

Categorical outcomes were compared between study groups using Chi square test /Fisher's Exact test (If the overall sample size was $<20$ or if the expected number in any one of the cells is $<5$, Fisher's exact test was used.) Indeandent sample $\mathrm{T}$ test / Mann Whitney $\mathrm{U}$ test was applied for numeric parameters comparison with categorical variables. $\mathrm{P}$ value $<0.05$ was considered statistically significant. IBM SPSS (version 22 Armonk, NY: IBM Corp.) was used for statistical analysis. ${ }^{10}$

\section{RESULTS}

A total of 300 subjects were included in the final analysis of which 58 were having PFD. Figure 1 shows the data of females with and without pelvic floor dysfunction. Majority of them 52(17.33\%) had Pelvic organ prolapse, followed by POP with UI, urinary incontinence and faecal incontinence was $1 \%, 0.67 \%$ and $0.33 \%$ respectively.

Among the females with PFD, 43 (74.14\%) were aged $>45$ years, $38(65.52 \%)$ had 2 or 3 children, and 12 $(20.69 \%)$ had $\geq 4$ children. $47(81.03 \%)$ had Vaginal Delivery. 8 (13.79\%) had no schooling, $41(70.69 \%)$ had education from class 1 to $10,37(63.79 \%)$ were no schooling and $13(22.41 \%)$ were unskilled workers. 36 (62.07\%) participants BMI was ranged between 25 to 34.99. $2 \%$ has dyspareunia (Table 1). Strong statistical significance was seen with age, number of children, mode of delivery and BMI (body mass index) in females with PFD ( $p$ value<0.005). There was no statistical significance with education, occupation and sexual symptoms in PFD.
Table 1: Distribution of study subjects according to baseline variables with $\mathrm{PFD}(\mathrm{n}=\mathbf{5 8})$.

\begin{tabular}{|c|c|c|}
\hline Baseline variables & Frequency & Percentage \\
\hline \multicolumn{3}{|l|}{ Age groups (yrs) } \\
\hline $18-25$ & 1 & 1.72 \\
\hline $26-35$ & 2 & 3.45 \\
\hline $36-45$ & 12 & 20.69 \\
\hline$>45$ & 43 & 74.14 \\
\hline \multicolumn{3}{|l|}{ Number of children } \\
\hline Nulli para & 2 & 3.45 \\
\hline One child & 6 & 10.34 \\
\hline $2-3$ & 38 & 65.52 \\
\hline$>4$ & 12 & 20.69 \\
\hline \multicolumn{3}{|l|}{ Type of delivery } \\
\hline Instrumental & 2 & 3.45 \\
\hline Caesarion & 7 & 12.07 \\
\hline Vaginal & 47 & 81.03 \\
\hline \multicolumn{3}{|l|}{ Education } \\
\hline No schooling & 8 & 13.79 \\
\hline Class $1-10$ & 41 & 70.69 \\
\hline Class 11- 12 & 6 & 10.34 \\
\hline UG & 2 & 3.45 \\
\hline PG & 1 & 1.72 \\
\hline \multicolumn{3}{|l|}{ Occupation } \\
\hline Housewife & 37 & 63.79 \\
\hline White collar & 6 & 10.34 \\
\hline Unskilled & 13 & 22.41 \\
\hline Semiskilled & 1 & 1.72 \\
\hline Skilled & 1 & 1.72 \\
\hline \multicolumn{3}{|l|}{ BMI index } \\
\hline $18-24.99$ & 22 & 37.93 \\
\hline $25-34.99$ & 36 & 62.07 \\
\hline$\geq 35$ & 0 & 0 \\
\hline $\begin{array}{l}\text { Dyspareunia } \\
\text { (Sexual symptoms) }\end{array}$ & 2 & 3.45 \\
\hline
\end{tabular}

Among study population the mean Age was 37.49 \pm 10.32 (19 to 63) and $180(60 \%)$ had vaginal delivery, 97 $(32.2 \%)$ had LSCS and $3(15 \%)$ of them had Forceps delivery. $257(85.66 \%)$ of them had completed their schooling, $34(11.3 \%)$ of them had not completed their schooling and $7(2.3 \%)$ of them completed they're Under Graduation. $183(61 \%)$ of them were homemakers, 86 $(28.7 \%)$ of them un-skilled workers, $23(7.66 \%)$ of them were Skilled labour and $8(2.7 \%)$ of them were Semiskilled (Table 2).

Among the study population $52(17.3 \%)$ had POP, 5 $(1.7 \%)$ of them had UI and $(0.3 \%)$ had FI. There was no association of age, number of children, occupation, BMI, education and 3 types of PFD and was not statistically significant. The p-value was not-significant for type of delivery, urinary incontinence index, vaizey incontinence score and sexual symptoms with the types of PFD. No statistical test was applied due to 0's in cells, \$ independent sample $\mathrm{T}$ test was applied for age and BMI and \#Mann Whitney $U$ test for number of chidren. These were not statistically significant (Table 3 ). 
Table 2: Comparison of baseline characteristics with PFD (n=300).

\begin{tabular}{|c|c|c|c|c|}
\hline \multirow{3}{*}{$\begin{array}{l}\text { Baseline } \\
\text { characteristics }\end{array}$} & \multicolumn{2}{|l|}{ PFD } & \multirow{3}{*}{ Chi square } & \multirow{3}{*}{ P value } \\
\hline & Women with PFD (n=58) & Women without PFD (n=242) & & \\
\hline & $\mathbf{N}(\%)$ & $\mathbf{N}(\%)$ & & \\
\hline \multicolumn{5}{|l|}{ Age group (yrs) } \\
\hline 18 To 25 & $1(1.72)$ & $60(24.79)$ & \multirow{4}{*}{118.945} & \multirow{4}{*}{$<0.001$} \\
\hline 26 To 35 & $2(3.45)$ & $55(22.73)$ & & \\
\hline 36 To 45 & $12(20.69)$ & $105(43.39)$ & & \\
\hline$>45$ & $43(74.14)$ & $22(9.09)$ & & \\
\hline \multicolumn{5}{|c|}{ Number of children } \\
\hline Nulli Para & $2(3.45)$ & $18(7.44)$ & \multirow{4}{*}{31.230} & \multirow{4}{*}{$<0.001$} \\
\hline 1 & $6(10.34)$ & $59(24.38)$ & & \\
\hline $2 \& 3$ & $38(65.52)$ & $159(65.7)$ & & \\
\hline$\geq 4$ & $12(20.69)$ & $6(2.48)$ & & \\
\hline \multicolumn{5}{|l|}{ Type of delivery } \\
\hline Caesarean section & $7(12.07)$ & $90(37.19)$ & \multirow{3}{*}{19.861} & \multirow{3}{*}{$<0.001$} \\
\hline Instrumental & $2(3.45)$ & $1(0.41)$ & & \\
\hline Vaginal delivery & $47(81.03)$ & $133(54.96)$ & & \\
\hline \multicolumn{5}{|l|}{ Education } \\
\hline No schooling & $8(13.79)$ & $26(10.74)$ & \multirow{5}{*}{4.596} & \multirow{5}{*}{0.331} \\
\hline Class 1 To 10 & $41(70.69)$ & $161(66.53)$ & & \\
\hline Class 11 and 12 & $6(10.34)$ & $49(20.25)$ & & \\
\hline UG & $2(3.45)$ & $5(2.07)$ & & \\
\hline PG & $1(1.72)$ & $1(0.41)$ & & \\
\hline \multicolumn{5}{|l|}{ Occupation } \\
\hline House wife & $37(63.79)$ & $146(60.33)$ & \multirow{5}{*}{3.148} & \multirow{5}{*}{0.533} \\
\hline White collar & $6(10.34)$ & $14(5.79)$ & & \\
\hline Unskilled & $13(22.41)$ & $73(30.17)$ & & \\
\hline Semi-skilled & $1(1.72)$ & $7(2.89)$ & & \\
\hline Skilled & $1(1.72)$ & $2(0.83)$ & & \\
\hline \multicolumn{5}{|l|}{ BMI classification } \\
\hline 18 To 24.99 & $22(37.93)$ & $82(33.88)$ & \multirow{3}{*}{$*$} & \multirow{3}{*}{$*$} \\
\hline 25 To 34.99 & $36(62.07)$ & $158(65.29)$ & & \\
\hline$\geq 35$ & $0(0)$ & $2(0.83)$ & & \\
\hline \multicolumn{5}{|l|}{ Sexual symptoms } \\
\hline Dyspareunia & $2(3.45)$ & $18(7.44)$ & \multirow{2}{*}{1.197} & \multirow{2}{*}{0.385} \\
\hline None & $56(96.55)$ & $224(92.56)$ & & \\
\hline
\end{tabular}

Table 3: Comparison of baseline characteristics with PFD ( $n=300)$.

\begin{tabular}{|c|c|c|c|c|}
\hline \multirow{2}{*}{ Parameter } & \multicolumn{3}{|l|}{ Groups } & \multirow{2}{*}{ P value } \\
\hline & POP $(n=52)$ & UI $(n=5)$ & FI $(n=1)$ & \\
\hline Age & $48.8 \pm 8.45$ & $52.40 \pm 4.56$ & $34 \pm 0$ & $0.134 \$$ \\
\hline Number of children & $3(1,2)$ & $2(1,1)$ & 2 & $0.46 \#$ \\
\hline \multicolumn{4}{|l|}{ Type of delivery } & \multirow{4}{*}{$*$} \\
\hline Forceps & $0(0 \%)$ & $1(20 \%)$ & $1(100 \%)$ & \\
\hline LSCS & $7(14.0 \%)$ & $0(0 \%)$ & $0(0 \%)$ & \\
\hline Vaginal delivery & $43(86 \%)$ & $4(80 \%)$ & $0(0 \%)$ & \\
\hline \multicolumn{4}{|l|}{ Education } & \multirow{5}{*}{$*$} \\
\hline No schooling & $7(13.5 \%)$ & $1(20 \%)$ & $0(0 \%)$ & \\
\hline Schooling & $43(82.7 \%)$ & $3(60 \%)$ & $1(100 \%)$ & \\
\hline Under graduation & $1(1.9 \%)$ & $1(20 \%)$ & $0(0 \%)$ & \\
\hline Post graduation & $1(1.9 \%)$ & $0(0 \%)$ & $0(0 \%)$ & \\
\hline
\end{tabular}

Continued. 


\begin{tabular}{|c|c|c|c|c|}
\hline \multirow{2}{*}{ Parameter } & \multicolumn{3}{|l|}{ Groups } & \multirow{2}{*}{$P$ value } \\
\hline & POP $(n=52)$ & UI $(\mathbf{n}=5)$ & FI $(n=1)$ & \\
\hline \multicolumn{4}{|l|}{ Occupation } & \multirow{5}{*}{ * } \\
\hline Home maker & $34(65.4 \%$ & $3(60 \%)$ & $0(0 \%)$ & \\
\hline Skilled & $5(9.6 \%)$ & $2(40 \%)$ & $0(0 \%)$ & \\
\hline Un-skilled & $12(23.1 \%)$ & $0(0 \%)$ & $1(100 \%)$ & \\
\hline Semi-skilled & $1(1.9 \%)$ & $0(0 \%)$ & $0(0 \%)$ & \\
\hline BMI & $27.51 \pm 4.44$ & $27.38 \pm 2.85$ & $23.6 \pm 0$ & $0.673 \$$ \\
\hline Urinary incontinence index & - & $6(5$ to 7$)$ & - & * \\
\hline Vaizey incontinence score & - & - & - & * \\
\hline POP Q & 2 (2 to 3$)$ & - & - & * \\
\hline \multicolumn{4}{|l|}{ Sexual symptoms } & \multirow{3}{*}{$*$} \\
\hline Dyspareunia & $0(0 \%)$ & $0(0 \%)$ & $1(100 \%)$ & \\
\hline None & $52(100 \%)$ & $5(100 \%)$ & $0 \quad(0 \%)$ & \\
\hline
\end{tabular}

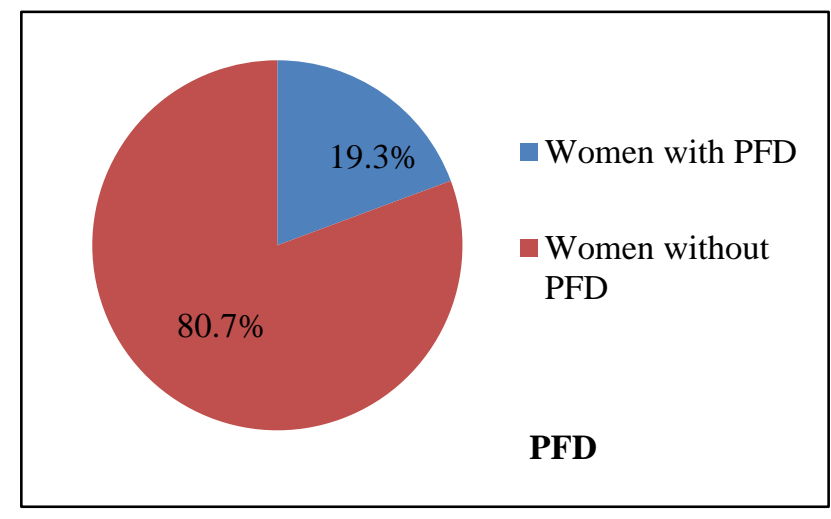

Figure 1: Pie chart of PFD in the study population $(\mathbf{n}=300)$.

\section{DISCUSSION}

The present study explored the prevalence of PFD and related factors in women. Out of 300 sample size, 58 of the women were diagnosed with PFD. Among them Majority were $>45$ years old $(74.14 \%)$, $90 \%$ of the women had $>2$ children, $47(81.03 \%)$ had vaginal delivery, $41(70.69 \%)$ of them had schooling from class 1 $10,37(63.79 \%)$ were housewives and $36(62.07 \%)$ had high BMI. Millions of women are affected with PFD globally.

PFDs are not only a major health problem but affect the quality of life of women reducing their productivity. Symptoms of urinary incontinence or faecal incontinence, pelvic organ prolapse, sexual dysfunction and chronic pain syndromes are different types of PFD which may occur separately or coexist in a single individual of which urinary incontinence and pelvic organ prolapse are the most common.

Pelvic organ prolapse is herniation of pelvic organs which include bladder, uterus, small bowel or rectal ampulla through levator hiatus. Urinary incontinence is the involuntary leakage of urine. ${ }^{11}$ PFDs cause serious economic, social, physical and psychological problems in women. Even with high prevalence and their debilitating effect on the quality of life, there are not many studies which assess the prevalence of PFDs, particularly in developing countries like India. Most of the PFD are treatable, but many women continue to live with the condition due to many reasons.

One of the main reasons for women not seeking medical treatment is the embarrassment and stigma attached with PFD and lack of knowledge. Clinical profiling will help to assess the magnitude of the problem. It will help to increase awareness of various PFD conditions, their risk factors and available treatment options.

A total of 300 subjects were included in the final analysis out of which 58 were having PFD. Among the study population, $19.33 \%$ of participants had one or more types of PFD and remaining $80.67 \%$ of participants were without PFD. This prevalence of PFD found in this study is in comparison to a study done in India by Rao et al, which showed a prevalence of $21.0 \%$ and in another study conducted by Wu et al, in the USA which showed a prevalence of $25.0 \% .^{7,9}$ On the other hand, in another study by Megabiaw et al, in Ethiopia reported a prevalence of $12.0 \%$, which is in contrast to the present study. ${ }^{12}$

Majority of participants with PFD were more than 45 years of age which is in comparison with a study by Hallock, which mentioned that prevalence of PFDs increased from $2.91 \%$ among 20 to 29 year old participants, to $16.16 \%$ among 70 years and older. ${ }^{8}$

Among the participants with Pelvic floor dysfunction $17.33 \%$ had Pelvic organ prolapse, followed by POP with urinary incontinence, urinary incontinence and faecal incontinence which were $1 \%, 0.67 \%$ and $0.33 \%$ respectively. This finding of pelvic organ prolapse in $17.33 \%$ of participants is in comparison to a study by Walker et al, where the mean prevalence for pelvic organ prolapse was $19.7 \%$ and in contrast to a study by Megabiaw et al, in which anatomical pelvic organ prolapse stage II-IV was detected in $55.1 \%$ of women. ${ }^{4,12}$ 
The percentage of participants with 2 and 3 children was almost same in participants with PFD and without PFD. It is reported in the literature that Pelvic floor muscles weaken after delivery. It was reported in a study by Hilde et al that pelvic floor muscle strength decreases after the first vaginal delivery. ${ }^{13}$

The finding in this study is in contrast from the present study. In a study by Özdemir et al, it was found that women who had 1-3 deliveries had the highest Pelvic floor muscle strength; and that this strength decreased as the number of deliveries increased. ${ }^{14}$ This may be considered as the reason for the percentage of participants with 2 and 3 children being the same in women with and without PFD.

$81.03 \%$ of participants with PFD and $54.96 \%$ without PFD had a vaginal delivery. The finding of a higher percentage of participants with vaginal delivery can be compared to that found in a study by MacLennan et al, which reported pelvic floor dysfunction in $58 \%$ of women who had a spontaneous vaginal delivery, compared with $43 \%$ of those who underwent caesarean section. ${ }^{15}$

It has also been reported in previous studies that increased pressure on the bladder during pregnancy causes an increase in the ureterovesical angle, and a decrease in the support of the bladder neck and urethra, which may be responsible for urethral hypermobility as well as UI. ${ }^{16}$ Denervation, disruption and damage to levator complex caused during vaginal delivery increase the risk of development of POP. Ureterovesical angle is found to be increased in women after childbirth compared to non-pregnant women. ${ }^{17}$

The finding of a higher percentage of vaginal deliveries in PFD participants in the present study and higher percentage of POP among other PFDs in this study can be compared to the findings in two studies one by Handa et al, in which it was reported that operative vaginal birth significantly increased the odds for all pelvic floor disorders, especially prolapse and in another study by Quiroz et al it was concluded that the odds of pelvic organ prolapse were almost 10 times higher after a single vaginal birth. ${ }^{18,19}$

Very less percentage of participants are educated to graduation level, and very less percentage of participants are working professionals in the present study. Because of this, the majority of participants may not have PFD knowledge. Absence of sufficient knowledge results in the belief that they are simply "a normal part of ageing," or being unaware that treatment options exist.

Additional barriers to presentation include personal embarrassment, being unaware that PFDs are medical conditions, and being unaware that treatment options exist. ${ }^{20}$ This is reported in a study by Chen et al. ${ }^{5}$ A study by Mandimika et al, mentions that increasing knowledge of these conditions has demonstrated to increase compliance with treatments. ${ }^{21}$

The pelvic floor is subjected to chronic stress in obese women which is due to elevated intra-abdominal pressure, and this may cause stress incontinence and other pelvic floor disorders. Additionally, it may affect the neuromuscular function of the genital tract and thereby contribute to the pelvic floor and urethral dysfunction. Age and parity are the two factors that work with obesity to cause an increased incidence of urodynamic stress incontinence. $^{22}$

The most important lifestyle factor is considered to be a high body mass index. The most probable mechanism of POP development among obese women is increase in intra-abdominal pressure which causes weakening of pelvic floor muscles and fascia. ${ }^{23}$ The present study finding indicates higher BMI ranging from 25 to 34.99 in majority of participants with PFD which is in comparison with a study by Hendrix et al, in which it was shown that percentage of prolapses increased with increased BMI values. $^{24}$

The major limitation of the study includes a hospital based and small number of samples recruited. Hence the results cannot be generalized on the whole. To clarify the issue a large sample size and different hospitals from other geographical areas should be considered that will reflect the overall situation.

\section{CONCLUSION}

The present study concluded a high prevalence of Pelvic floor dysfunction similar to the reported global trends. Age, mode of delivery, obesity and number of children, BMI were found to be risk factors associated with pelvic floor dysfunction. Knowledge and education about the above risk factors can help in preventing PFDs to some extent. The participants with PFD mostly had a low level of education which can be linked with lack of knowledge regarding PFD conditions and the ignorance to the fact that early medical intervention will help in conservative management of PFD.

\section{ACKNOWLEDGMENTS}

Authors acknowledge the technical support in data entry, analysis and manuscript editing by "Evidencian Research Associates".

\section{Funding: No funding sources \\ Conflict of interest: None declared \\ Ethical approval: The study was approved by the Institutional Ethics Committee}

\section{REFERENCES}

1. Jundt K, Peschers U, Kentenich H. The investigation and treatment of female pelvic floor 
dysfunction. Dtsch Arztebl Int. 2015;112(3334):564-74.

2. Dheresa M, Worku A, Oljira L, Mengiste B, Assefa $\mathrm{N}$, Berhane $\mathrm{Y}$. One in five women suffer from pelvic floor disorders in Kersa district Eastern Ethiopia: a community-based study. BMC Womens Health. 2018;18(1):95.

3. Zargham M, Alizadeh F, Moayednia A, Haghdani S, Mahdavi K. The role of pelvic organs prolapse in the etiology of urinary incontinence in women. Adv Biomed Res. 2013;2:22.

4. Walker GJ, Gunasekera P. Pelvic organ prolapse and incontinence in developing countries: review of prevalence and risk factors. Int Urogynecol $\mathrm{J}$. 2011;22(2):127-35.

5. Chen CCG, Cox JT, Yuan C, Thomaier L, Dutta S. Knowledge of pelvic floor disorders in women seeking primary care: a cross-sectional study. BMC Fam Pract. 2019;20(1):70.

6. Tosun G, Peker N, Tosun ÖÇ, Yeniel ÖA, Ergenoğlu AM, Elvan A, et al. Pelvic floor muscle function and symptoms of dysfunctions in midwifes and nurses of reproductive age with and without pelvic floor dysfunction. Taiwan J Obstet Gynecol. 2019;58(4):505-13.

7. Wu JM, Vaughan CP, Goode PS, Redden DT, Burgio KL, Richter HE, et al. Prevalence and trends of symptomatic pelvic floor disorders in US women. Obstet Gynecol. 2014;123(1):141.

8. Hallock JL, Handa VL. The epidemiology of pelvic floor disorders and childbirth: an update. Obstet Gynecol Clin North Am. 2016;43(1):1-13.

9. Rao KB, Nayak S, Kumar P, Kamath V, Kamath A. Prevalence of pelvic floor dysfunction among married women of Udupi taluk, Karnataka, India. J Women's Health Care. 2015;4(236):2167-70.

10. IBM Corp. Released 2013. IBM SPSS Statistics for Windows, Version 22.0. Armonk, NY: IBM Corp.

11. Kady OSH, Tamara TF, Sabaa HAEM, Hafez AHMS. Assessment of the prevalence of pelvic floor disorders in both vaginal and cesarean deliveries and their impact on the quality of life. Egypt J Hosp Med. 2017;68(2):1252-6.

12. Megabiaw B, Adefris M, Rortveit G, Degu G, Muleta M, Blystad A, et al. Pelvic floor disorders among women in Dabat district, northwest Ethiopia: a pilot study. Int Urogynecol J. 2013;24(7):1135-43.

13. Hilde G, Jensen SJ, Siafarikas F, Engh ME, Braekken IH, Bo K. Impact of childbirth and mode of delivery on vaginal resting pressure and on pelvic floor muscle strength and endurance. Am J Obstet Gynecol. 2013;208(1):50-7.
14. Ozdemir OC, Bakar Y, Ozengin N, Duran B. The effect of parity on pelvic floor muscle strength and quality of life in women with urinary incontinence: a cross sectional study. J Phys Ther Sci. 2015;27(7):2133-7.

15. MacLennan AH, Taylor AW, Wilson DH, Wilson D. The prevalence of pelvic floor disorders and their relationship to gender, age, parity and mode of delivery. BJOG. 2000;107(12):1460-70.

16. Allen RE, Hosker GL, Smith AR, Warrell DW. Pelvic floor damage and childbirth: a neurophysiological study. Br J Obstet Gynaecol. 1990;97(9):770-9.

17. Wijma J, Potters AE, de Wolf BT, Tinga DJ, Aarnoudse JG. Anatomical and functional changes in the lower urinary tract following spontaneous vaginal delivery. BJOG. 2003;110(7):658-63.

18. Handa VL, Blomquist JL, Knoepp LR, Hoskey KA, McDermott KC, Munoz A. Pelvic floor disorders 510 years after vaginal or cesarean childbirth. Obstet Gynecol. 2011;118(4):777-84.

19. Quiroz LH, Munoz A, Shippey SH, Gutman RE, Handa VL. Vaginal parity and pelvic organ prolapse. J Reprod Med. 2010;55(3-4):93-8.

20. Basu M, Duckett JR. Barriers to seeking treatment for women with persistent or recurrent symptoms in urogynaecology. BJOG. 2009;116(5):726-30.

21. Mandimika CL, William M, Mcpencow AM, AeuMuro L, Miller D, Connell KA, et al. Racial disparities in knowledge of pelvic floor disorders among community-dwelling women. Female Pelvic Med Reconstr Surg. 2015;21(5):287.

22. Jain P, Parsons M. The effects of obesity on the pelvic floor. Obstet Gynecol. 2011;13(3):133-42.

23. Lee UJ, Kerkhof MH, Leijsen SA, Heesakkers JP. Obesity and pelvic organ prolapse. Curr Opin Urol. 2017;27(5):428-34.

24. Hendrix SL, Clark A, Nygaard I, Aragaki A, Barnabei V, McTiernan A. Pelvic organ prolapse in the women's health initiative: gravity and gravidity. Am J Obstet Gynecol. s2002;186(6):1160-6.

Cite this article as: Gaddam R, Gangadharan K, Shivaraju P, Basappa PK. Prevalence of pelvic floor dysfunction in women attending obstetrics and gynaecology OPD at PES Institute of Medical Sciences and Research, Kuppam. Int J Reprod Contracept Obstet Gynecol 2020;9:5087-93. 